\title{
Enhanced Thermophysical Properties of NEILs as Heat Transfer Fluids for Solar Thermal Applications
}

\author{
Titan C. Paul ${ }^{1}$, A.K.M. M. Morshed ${ }^{2}$, Elise B. Fox ${ }^{3}$, Jamil A. Khan ${ }^{1, *}$ \\ ${ }^{1}$ Department of Mechanical Engineering, University of South Craolina, Columbia, SC, USA \\ ${ }^{2}$ Department of Mechanical Engineering, Bangladesh University of Engineering and Technology, Dhaka, \\ Bangladesh \\ ${ }^{3}$ Savannah River National Laboratory, Aiken, SC, USA
}

\begin{abstract}
Thermophysical properties of base ionic liquids (ILs) and nanoparticle enhanced ionic liquids (NEILs) were measured experimentally. NEILs are formed by dispersing different wt\% $(0.5$, 1.0, and 2.5) of $\mathrm{Al}_{2} \mathrm{O}_{3}$ nanoparticles in four base ILs. NEILs show enhanced thermal conductivity, viscosity, and heat capacity compared to the base ILs. NEILs show shear thinning behavior at all the measured temperatures and the enhancement of viscosity was predicted by the aggregation model with high aggregation factor. Maximum thermal conductivity enhancement was observed by $\sim 11 \%$ for 2.5 wt $\%$ NEILs. The experimental effective thermal conductivity could not predicted by the aggregation model with the same aggregation factor. However, the theoretical model considering interfacial layer of the particle/liquid interface (with interfacial layer thickness $2 \mathrm{~nm}$ and interfacial layer thermal conductivity, $k_{l r}=3 k_{B L}$ ) could predict the effective thermal conductivity of NEILs. Heat capacity of NEILs shows much higher value compared to the base ILs and the theoretical model could not predict that enhancement. The strong interaction between the nanoparticles surface to ions of the ionic liquids was considered as the potential factor for those enhancements of thermophysical properties.
\end{abstract}

Keywords: Ionic Liquids; Nanoparticle Enhanced Ionic Liquids (NEILs); Rheological Behavior; Thermal Conductivity; Heat Capacity; Heat Transfer Fluid.

*Corresponding Author

Dr. Jamil A Khan

Department of Mechanical Engineering

University of South Carolina, Columbia, SC 29208

E-mail: khan@cec.sc.edu

Phone: 1-803-777-1578 


\section{INTRODUCTION}

The environmental community and energy researchers are concerned about global warming and the emission of $\mathrm{CO}_{2}$ from the burning of fossil fuels in energy production [1]. People are looking for environmental friendly and energy efficient alternate sources of energy. From the many options of renewable energy, solar energy is one of the most abundant alternate energy sources in the world [2]. Solar energy can be harvested by means of direct conversion of sunlight into energy with photovoltaic effect which is called solar cell and by absorbing heat from the sunlight which is called solar thermal collector [3]. Solar cells face the problem of lower efficiency and higher cost effective ratio, whereas solar thermal collectors possess superior performance over the solar cell [4]. Concentrated solar power (CSP) is one of the forms of solar thermal collector, which is the growing technology for electricity generation. On commercial level application 14 MW Solar Energy Generating System or SEGS plant was built first in California, US in 1980 and in 2012 it is become 2553 MW worldwide. Also, 2000 MW plants are under construction all over the world [5]. Ashouri et al. [6] have studied parabolic Trough solar collector driven by Kalina cycle and compared with the conventional fuel driven Kalina cycle. They reported that solar collector has the higher levelized cost than the fuel driven cycle but solar collector save huge amount of fuel burning that produces enormous $\mathrm{CO}_{2}$ emission. Organic Rankine cycle (ORC) was integrated with CSP system with different working fluids [7], and reported that the cycle running with benzene has the higher thermal efficiency.

In CSP system, electricity is generated by concentrating sunlight from a large area using mirrors or lenses and stored in heat transfer fluid (HTF). Later on the energy of those HTF is used to produce steam for power generation by using conventional Rankine cycle [8]. The energy efficiency of the CSP system is mostly dependent on the operating temperature and thermal stability of the HTF. Currently, the commercially available and used HTFs are Therminol VP-1 (eutectic mixture of biphenyl and diphenyl oxide), molten salts, and mineral oil. Therminol VP-1 has a high vapor pressure at higher operating temperature which is harmful to the storage tank [9]. Molten salts have a higher operating temperature over $500^{\circ} \mathrm{C}$ but have higher melting temperatures which help to freeze up the liquid during the winter season [10], and mineral oil has lower decomposition temperature [11]. The above mentioned properties of currently used HTFs 
are affecting the energy storage capacity and reducing the overall system efficiency, resulting in increased operating cost. Therefore, there is an acute need for the new energy-efficient HTF.

Ionic liquids (ILs) are the organic salts having a low melting point (below $100^{\circ} \mathrm{C}$ ), which are already considered as a potential candidate for HTF in the solar thermal collector [12] and potential replacement of several organic solvents in chemical industry for reaction and separation systems [13]. The great interests of ILs are due to their excellent physical and chemical properties including negligible vapor pressure, high thermal stability, high ionic conductivities, high solvating capability, [14] and exposure to air and moisture stable [15]. However, thermophysical properties of ILs can be enhanced further by dispersing small percentage of nanoparticles, which is called Nanoparticle Enhanced Ionic Liquids (NEILs). Bridges et al. [16] have reported higher heat capacity of $\mathrm{Al}_{2} \mathrm{O}_{3}$ nanoparticles enhanced ILs without detrimental effect on the thermal stability. Fox et al. [17] have studied different nanoparticles effect on thermophysical properties of NEILs and reported that whisker-shaped $\mathrm{Al}_{2} \mathrm{O}_{3}$ nanoparticles show highest thermal conductivity enhancement. Paul et al. [18-19] have reported the higher forced convection heat transfer coefficients [18] and deterioration of the natural convection [19] heat transfer of NEILs compared to base ILs. Nieto de Castro et al. [20] have studied several imidazolium and pyrrolidinium ILs and multi wall carbon nanotubes (MWCNTs) based IoNanofluids (ionic liquid based nanofluids) and reported enhanced thermal conductivity and heat capacity. Shear thinning behavior and favorable friction reduction properties of ILs based nanofluids was observed by Wang et al. [21]. They have performed their studies on IoNanofluids containing 1-butyl-3-methylimidazolium hexafluorophosphate ([Bmim][PF 6$]$ ) IL and gold nanoparticle. Wang et al. [22] have studied the thermophysical properties of 1-hexyl-3methylimidazolium tetra-fluoroborate ([HMIM]BF $)$ IL based IoNanofluids with grapheme (GE) and MWCNTs. They reported thermal conductivity of IoNanofluids increases, but heat capacity decreases with nanoparticles concentration. Menbari et al. [23] have studied CuO/Water nanofluids effect on direct absorption concentrating solar collector and found higher thermal efficiency of the collector. Although several research groups work on thermophysical properties of NEILs, the mechanisms of thermophysical properties enhancement of NEILs are under investigation. 
This paper presents the rheological behavior, thermal conductivity, and heat capacity of NEILs containing $\mathrm{Al}_{2} \mathrm{O}_{3}$ nanoparticles at different concentration (0.5\%, $1.0 \%$, and $2.5 \%$ by wt) with $\left[\mathrm{C}_{4} \mathrm{mim}\right]\left[\mathrm{NTf}_{2}\right],\left[\mathrm{C}_{4} \mathrm{mmim}\right]\left[\mathrm{NTf}_{2}\right],\left[\mathrm{C}_{4} \mathrm{mpyrr}\right]\left[\mathrm{NTf}_{2}\right]$, and $\left[\mathrm{N}_{4111}\right]\left[\mathrm{NTf}_{2}\right]$ ILs. The rheological behavior, thermal conductivity, and heat capacity were studied within the temperature ranges 20$90^{\circ} \mathrm{C}, 10-70^{\circ} \mathrm{C}$, and $25-345^{\circ} \mathrm{C}$ respectively. The experimental data were compared with the existing theoretical models and plausible reasons of enhancement of thermophysical properties are discussed.

\section{NOMENCLATURE}

$\begin{array}{lll}T & \text { Temperature } & {[\mathrm{K}]} \\ k & \text { Thermal conductivity } & {[\mathrm{W} / \mathrm{m} . \mathrm{K}]} \\ A, B, C & \text { Constant } & {[\sim]} \\ c_{p} & \text { Heat capacity } & {[\mathrm{J} / \mathrm{g} . \mathrm{K}]} \\ D & \text { Fractal index } & {[\sim]} \\ h & \text { Interfacial layer thickness } & {[\mathrm{nm}]} \\ a & \text { Average radius } & {[\mathrm{nm}]}\end{array}$

\section{GREEK SYMBOLS}

$\begin{array}{lll}\gamma, \gamma_{1} & \text { Constant } & {[\sim]} \\ \rho & \text { Density } & {\left[\mathrm{kg} / \mathrm{m}^{3}\right]} \\ \mu & \text { Dynamic viscosity } & {[\text { centipoise }]} \\ \phi & \text { Nanoparticle volume fraction } & {[\sim]} \\ \phi_{m} & \text { Maximum particle packing fraction } & {[\sim]} \\ \phi_{a} & \text { Effective volume fraction of aggregates } & {[\sim]}\end{array}$

\section{SUBSCRIPTS}

NEIL Nanoparticle enhanced ionic liquid

$B L \quad$ Base liquid

n Nanoparticle

a Aggregate

lr Interfacial layer 


\section{EXPERIMENTAL MEASUREMENTS}

\subsection{Materials and Synthesis of Nanoparticle Enhanced Ionic Liquids (NEILs)}

The experimental investigated base ionic liquids (ILs) are 1-butyl-3-methylimidazolium bis $\{$ (trifluoromethyl)sulfonyl $\}$ imide $\left(\left[\mathrm{C}_{4} \mathrm{mim}\right]\left[\mathrm{NTf}_{2}\right]\right)$; Chemical Abstracts Service (CAS) registry number: 174899-83-3; molecular formula: $\mathrm{C}_{10} \mathrm{H}_{15} \mathrm{~F}_{6} \mathrm{~N}_{3} \mathrm{O}_{4} \mathrm{~S}_{2}$; molecular weight: 419.36 $\mathrm{g} / \mathrm{mol}$, N-butyl-N-methylpyrrolidinium bis\{trifluoromethyl)sulfonyl $\}$ imide $\left(\left[\mathrm{C}_{4} \mathrm{mpyrr}\right]\left[\mathrm{NTf}_{2}\right]\right)$; CAS: 223437-11-4; molecular formula: $\mathrm{C}_{11} \mathrm{H}_{20} \mathrm{~F}_{6} \mathrm{~N}_{2} \mathrm{O}_{4} \mathrm{~S}_{2}$; molecular weight: $422.41 \mathrm{~g} / \mathrm{mol}$, Nbutyl-N,N,N-trimetylammonium bis(trifluormethylsulfonyl)imide ([ $\left.\left.\mathrm{N}_{4111}\right]\left[\mathrm{NTf}_{2}\right]\right)$; CAS: 25827375-5; molecular formula: $\mathrm{C}_{9} \mathrm{H}_{18} \mathrm{~F}_{6} \mathrm{~N}_{2} \mathrm{O}_{4} \mathrm{~S}_{2}$; molecular weight: $396.37 \mathrm{~g} / \mathrm{mol}$, and 1-butyl-2, 3dimethylimidazolium bis(trifluoromethylsulfonyl)imide, ([ $\left.\left.\mathrm{C}_{4} \mathrm{mmim}\right]\left[\mathrm{NTf}_{2}\right]\right)$ CAS 350493-08-2 molecular formula: $\mathrm{C}_{11} \mathrm{H}_{17} \mathrm{~F}_{6} \mathrm{~N}_{3} \mathrm{O}_{4} \mathrm{~S}_{2}$ : molecular weight: $433.39 \mathrm{~g} / \mathrm{mol}$. $99 \%$ pure ILs were purchased from io-li-tec Company (Germany) [24] . The chemical structure of cation and anion of all ILs are shown in Fig.1.

$\mathrm{Al}_{2} \mathrm{O}_{3}$ nanoparticles were purchased from Sigma-Aldrich, USA [25]. Nanoparticles are $\gamma$-phase with particle size $<50 \mathrm{~nm}(\mathrm{TEM})$, and surface area $>40 \mathrm{~m}^{2} / \mathrm{g}$ (BET). $\mathrm{Al}_{2} \mathrm{O}_{3}$ were dispersed in the base ILs using a vortex mixture (Mini Vortexture from Fisher Scientific) to produce NEILs which was further agitated for $\sim 90$ min to break any possible agglomeration of nanoparticles. The weight percentage of nanoparticles were $0.5,1.0$, and 2.5 . The thermophysical properties measurements were done just after synthesis of NEILs. SEM image of the $\mathrm{Al}_{2} \mathrm{O}_{3}$ nanoparticles and a flow diagram of NEILs preparation is presented in the Fig. 2.

\subsection{Rheological behavior, thermal conductivity, and heat capacity measurements}

Rheological behavior of base ILs and NEILs was measured using cone and plate type rotary viscometer (LVDV-II+ProCP, from Brookfield Engineering Co.) [26]. The sample size required for the cone and plate arrangement is $1 \mathrm{~mL}$. The cone and plate arrangement have a thermal jacket to maintain a constant sample temperature within accuracy of $\pm 0.1^{\circ} \mathrm{C}$. A thermal bath

(Thermo NESLAB) was used to maintain constant temperature of the measuring sample. 
Temperature accuracy of the bath is within $\pm 0.01^{\circ} \mathrm{C}$. The viscometer was calibrated by using standard oil.

Thermal conductivity of base ILs and NEILs were measured using KD2 Pro thermal property analyzer (Decagon Device, USA) [27]. The measurement principle is based on the transient hot wire method. The meter has a probe of $60 \mathrm{~mm}$ length and $1.3 \mathrm{~mm}$ diameter with a heating element and a thermoresistor that is inserted vertically into the test sample. The probe is connected to a microcontroller for controlling and conducting the measurements. Before using it for ILs and NEILs measurements, the meter was calibrated with distilled water and standard glycerin. The same thermal bath was used to maintain the constant sample temperature.

Heat capacity of ILs and NEILs were measured using Differential Scanning Calorimetry (DSC Q2000 from TA instruments Inc.) [28]. The sample having an average mass of $12.89 \mathrm{mg}$ was placed in a standard aluminum hermetic pan which is covered with a lid. Nitrogen was used as the cooling system at a flow rate of $40 \mathrm{ml} / \mathrm{min}$ and DSC was operated at a heating rate of $10^{\circ} \mathrm{C} / \mathrm{min}$. Three independent runs were performed using reported experimental procedures [29].

Dispersion of nanoparticles into ILs was observed by an Olympus ix70 inverted microscope. Also, the nanoparticles size distribution into NEILs was observed by using the time resolved dynamic light scattering (TRDLS) technique.

\section{RESULTS AND DISCUSSION}

\subsection{Rheological behavior of NEILs}

The rheological behavior of base ILs and 0.5, 1.0, and $2.5 \mathrm{wt} \% \mathrm{Al}_{2} \mathrm{O}_{3}$ NEILs was measured for different temperature ranging from $20-90^{\circ} \mathrm{C}$. Fig. 3(a) shows the rheological behavior of $\left[\mathrm{C}_{4} \mathrm{mmim}\right]\left[\mathrm{NTf}_{2}\right]$ IL and NEILs at $30^{\circ} \mathrm{C}$. The base IL shows that the shear viscosity is independent of shear rate which shows the Newtonian behavior of the IL. It is clear from the Fig. 3(a) that NEILs shows non Newtonian shear thinning behavior, which means the shear viscosity is higher in low shear rate and shear viscosity decreases with the shear rate increases. Fig. 3(b) represents the rheological behavior of $0.5 \mathrm{wt} \%$ of four NEILs at $30^{\circ} \mathrm{C}$ and it is clear that all of the NEILs show shear thinning behavior. The rheological behavior of $1.0 \mathrm{wt} \%\left[\mathrm{C}_{4} \mathrm{mmim}\right]\left[\mathrm{NTf}_{2}\right]$ NEILs at different temperatures is presented in Fig. 3(c) and shear thinning behavior observed at all measured temperatures. The same shear thinning behaviors of ILs based nanofluids were 
observed by Wang et al. [21]. It is also observed that the shear viscosity shows the strong temperature dependency that is clearer in Fig. 3(d), where the viscosity of base $\left[\mathrm{C}_{4} \mathrm{mmim}\right]\left[\mathrm{NTf}_{2}\right]$ IL and NEILs is presented as a function of temperature. The temperature dependent viscosity data of NEILs were found to be fit very well with the Eq. 1 [30] and is presented in Fig. 3(e):

$$
\ln \mu=A+\frac{1000 \cdot B}{(T+C)}
$$

where $\mu$ is the shear viscosity, $T$ is the temperature in Kelvin $(\mathrm{K})$ unit, and A, B, and $\mathrm{C}$ are the constants.

Fig. 4 shows the viscosity of four ILs and NEILs at $30^{\circ} \mathrm{C}$ and it is clear that $2.5 \mathrm{wt} \%$ NEILs shows much higher viscosity compared to the base ILs and $\left[\mathrm{C}_{4} \mathrm{mim}\right]\left[\mathrm{NTf}_{2}\right]$ shows lowest viscosity of all four ILs and NEILs. The effective viscosity of $\left[\mathrm{C}_{4} \mathrm{mmim}\right]\left[\mathrm{NTf}_{2}\right]$ NEILs at $30^{\circ} \mathrm{C}$ as a function of the nanoparticles volume fraction is presented in Fig. 5 and it is clear that viscosity enhancement with nanoparticle volume fraction is nonlinear. The experimental results of viscosity enhancement with nanoparticles concentration were compared with numerous theoretical models.

Firstly, the Einstein's model [31] for calculating viscosity of fluid containing low volume fraction $(<0.02)$ of spherical particles was considered:

$$
\frac{\mu_{N E I L}}{\mu_{B L}}=1+2.5 \phi
$$

Brinkman [32] modified the Einstein's model for fluid containing high concentration nanoparticles:

$$
\frac{\mu_{N E I L}}{\mu_{B L}}=\frac{1}{(1-\phi)^{2.5}}
$$

After that, Batchelor [33] modified the Einstein's model with considering the Brownian motion of particles in nanofluids:

$$
\frac{\mu_{N E I L}}{\mu_{B L}}=1+2.5 \phi+6.2 \phi^{2}
$$


where $\mu_{N E I L}$ and $\mu_{B L}$ are the viscosity of NEIL and base liquid, and $\phi$ is the nanoparticle volume fraction. Fig.5 shows that the above mentioned model failed to predict the experimental results and predicted effective viscosity shows lower value compared to the experimental measurements. The models (Eq. 2-4) only considered the nanoparticles volume fraction and did not take into account other effects like the agglomeration of nanoparticles, liquid layering on nanoparticles which are common for the NEILs.

The present experimental results, then tried to explain considering the agglomeration of nanoparticles in NEILs. Nielson [34] proposed the power law model considering the agglomeration packing fraction for high concentration of the nanoparticles:

$$
\frac{\mu_{N E I L}}{\mu_{B L}}=(1+1.5 \phi) e^{\frac{\phi}{\left(1-\phi_{m}\right)}}
$$

where $\phi_{m}$ is the maximum particle packing fraction which is typically considered 0.605 . This model also underpredict the experimental results which can be observed in Fig.5.

Finally the Krieger-Dougherty (K-D) model [35] was considered to predict the experimental results take into consideration the maximum packing fraction and effect of variable packing fractions:

$$
\frac{\mu_{N E I L}}{\mu_{B L}}=\left(1-\frac{\phi_{a}}{\phi_{m}}\right)^{-[\eta] \phi_{m}}
$$

where the typical value of the intrinsic viscosity $[\eta]$ is 2.5 and $\phi_{a}$ is the effective volume fraction of aggregates which is given by the ratio of the radii of aggregate and primary nanoparticles:

$$
\phi_{a}=\phi\left(\frac{a_{a}}{a}\right)^{3-D}
$$

where, $a_{a}$ and $a$ are the average radii of the aggregate and primary nanoparticles respectively, D is the fractal index, and the typical value of fractal index is 1.8 for nanofluids. Finally, the model can be rearranged as:

$$
\frac{\mu_{N E I L}}{\mu_{B L}}=\left(1-\frac{\phi}{0.605}\left(\frac{a_{a}}{a}\right)^{1.2}\right)^{-1.5125}
$$


The experimental results were fitted with the Eq. (8) at aggregation factor $\left(\frac{a_{a}}{a}=21.5\right)$ and are presented in Fig. 5. In literature, aggregation factor was observed up to 16 for nitrate-silica nanofluids [36]. The aggregation of NEILs was also observed by Fox et al. [16], and they found that the $\left[\mathrm{C}_{4} \mathrm{mmim}\right]\left[\mathrm{NTf}_{2}\right]+\mathrm{Al}_{2} \mathrm{O}_{3}$ NEILs average cluster size was average $100 \mu \mathrm{m}$ where the primary particle size was $<50 \mathrm{~nm}$. For better observation of the experimental results, the optical image of $0.5 \mathrm{wt} \%$ NEILs was also presented in Fig. 6. It is clear that the nanoparticles have agglomerated in ILs. The same particle agglomeration of NEILs was also observed by the DLS particle size measurement in Fig.7. It was observed that the average hydrodynamic radii of nanoparticles increase with time. It is clear that the particles have a huge tendency inagglomerate and this might be one reason for the enormous enhancement of viscosity. However, including this phenomenon, there may be other variables like the interaction of ILs and nanoparticles surface needed to take into consideration for further discussion.

\subsection{Effective thermal conductivity of NEILs}

The thermal conductivity of all base ILs and NEILs was measured within $10-70^{\circ} \mathrm{C}$ temperature ranges. Fig.8(a) shows the thermal conductivity of four ILs and NEILs at $30^{\circ} \mathrm{C}$ and it is clear that 2.5 wt\% NEILs shows the highest enhancement of thermal conductivity. The enhanced percentage is clearer in the Fig.8(b) where, the effective thermal conductivity of $\left[\mathrm{C}_{4} \mathrm{mmim}\right]\left[\mathrm{NTf}_{2}\right]$ NEILs is presented as a function of temperature. It is clear from the Fig.8(b) that the thermal conductivity increases with the wt $\%$ of nanoparticles over the measured temperature range and there is a weak temperature dependency observed. From all of the NEILs the maximum enhancement was observed $\sim 11 \%$ for $2.5 \mathrm{wt} \%$ loading of nanoparticles. The possible mechanisms of thermal conductivity enhancement of traditional nanofluids are Brownian motion of nanoparticles, the nature of heat transport to the nanoparticles [37], liquid layering in liquid/nanoparticle surface interface [38], and the effect of nanoparticle cluster and structure [39]. To understand the exact mechanism of thermal conductivity enhancement, the experimental results were compared with the conventional models for thermal conductivity prediction. The Maxwell model [40] for spherical nanoparticles with homogeneous suspension was considered:

$$
\frac{k_{N E I L}}{k_{B L}}=\frac{k_{n}+2 k_{B L}-2 \phi\left(k_{B L}-k_{n}\right)}{k_{n}+2 k_{B L}+\phi\left(k_{B L}-k_{n}\right)}
$$


where $k_{N E I L}, k_{B L}, k_{n}=36 \mathrm{~W} / m K$ are the thermal conductivity of NEIL, base IL, and $\mathrm{Al}_{2} \mathrm{O}_{3}$ nanoparticles respectively. $\Phi$ is the nanoparticle volume fraction. This model underpredicts the experimental results because it only considers the nanoparticles volume fraction and thermal conductivity of base liquid and nanoparticles.

The Bruggeman model [41] predicted little bit more enhancement than the Maxwell model because it considers the clustering of nanoparticles.The model for calculating the thermal conductivity of nanofluids is:

$k_{N E I L}=\frac{1}{4}\left[(3 \phi-1) k_{n}+(2-3 \phi) k_{B L}\right]+\frac{k_{B L}}{4} \sqrt{\Delta}$

$\Delta=\left[(3 \phi-1)^{2}\left(\frac{k_{n}}{k_{B L}}\right)^{2}+(2-3 \phi)^{2}+2\left(2+9 \phi-9 \phi^{2}\right)\left(\frac{k_{n}}{k_{B L}}\right)\right]$

The aggregation of nanoparticles was considered to predict the effective thermal conductivity [42] and the aggregation factor $\left(\frac{a_{a}}{a}=21.5\right)$ was considered the same as the shear viscosity predicted. Maxwell model can be rearranged with the aggregation factor:

$\frac{k_{N E I L}}{k_{B L}}=\frac{k_{a}+2 k_{B L}-2 \phi_{a}\left(k_{B L}-k_{a}\right)}{k_{a}+2 k_{B L}+\phi_{a}\left(k_{B L}-k_{a}\right)}$

where $k_{a}$ is the aggregates thermal conductivity

The aggregates thermal conductivity was calculated from the correlation:

$\frac{k_{a}}{k_{B L}}=\frac{1}{4}\left\{\left(3 \phi_{\text {in }}-1\right) \frac{k_{n}}{k_{B L}}+\left(3\left(1-\phi_{\text {in }}\right)-1\right)+\left[\left(\left(3 \phi_{\text {in }}-1\right) \frac{k_{n}}{k_{B L}}+\left(3\left(1-\phi_{\text {in }}\right)-1\right)\right)^{2}+\right.\right.$ $\left.\left.8 \frac{k_{n}}{k_{B L}}\right]^{1 / 2}\right\}$

where $\phi_{i n}\left(=\left(\frac{a_{a}}{a}\right)^{D-3}\right)$ is the aggregates solid volume fraction.

Although considering clustering and aggregation give higher effective thermal conductivity compared to the the Maxwell model, it is clear from the Fig. 8(c) that still could not predict the experimental effective thermal conductivity. However, the predicted and experimental results are consistent with previously studied thermal conductivity measurements [20]. 
The interfacial layer of nanoparticles in NEILs was considered to predict the effective thermal conductivity of NEILs by Murshed et al.'s model [43]:

$k_{N E I L}=\frac{\left(k_{n}-k_{l r}\right) \phi k_{l r}\left[2 \gamma_{1}^{2}-\gamma^{2}+1\right]+\left(k_{n}+2 k_{l r}\right) \gamma_{1}^{2}\left[\phi \gamma^{2}\left(k_{l r}-k_{B L}\right)+k_{B L}\right]}{\gamma_{1}^{2}\left(k_{n}+2 k_{l r}\right)-\left(k_{n}-k_{l r}\right) \phi\left[\gamma_{1}^{2}+\gamma^{2}-1\right]}$

where $k_{l r}$ is the thermal conductivity of interfacial layer which would be $k_{B L}<k_{l r}<k_{n}$; here $k_{l r}=3 k_{B L}$ considered.

$\gamma=1+\frac{h}{a}$

$\gamma_{1}=1+\frac{h}{2 a}$

where $h$ is the interfacial layer thickness, taken into consideration $h=2 \mathrm{~nm}$ and $a=20 \mathrm{~nm}$. As of Fig. 8(c) the enhancement of thermal conductivity of NEILs is predicted well with the interfactial layer model. Nieto de Castro et al.[20] also used the Murshed's model to predict the thermal conductivity of $\left[\mathrm{C}_{4} \mathrm{mim}\right]\left[\mathrm{NTf}_{2}\right]$ and multi wall carbon nanotubes (MWCNT) considering $h=1 \mathrm{~nm}$ and $k_{l r}=1.2 k_{B L}$ and they found reasonably good agreement with the experimental results. Although the interfacial layer model predicted well the experimental thermal conductivity with arbitrary interfacial layer thickness and thermal conductivity, there may be other parameter like complex interactions of nanoparticles surface with ILs which should be considered. In literature, there is evidence of strong interactions of nanoparticles and ILs [44-45]. Molecular dynamic simulations of nanofluids containing ruthenium nanoparticle in ILs were performed by Pensado et al. [44] and they reported that nanoparticles are in contact with the anion and cation of ILs. Complex interaction of IL and Al-O surface was observed by the theoretical model [45].

\subsection{Heat Capacity}

The heat capacity of all four ILs and 0.5, 1.0, and $2.5 \mathrm{wt} \%$ NEILs was measured within the temperature ranges $25-345^{\circ} \mathrm{C}$. Fig.9(a) shows the heat capacity of four ILs and NEILs at $30^{\circ} \mathrm{C}$ and it is clear that $2.5 \mathrm{wt} \%$ NEILs shows much higher heat capacity compared to base ILs. The heat capacity of $\left[\mathrm{C}_{4} \mathrm{mmim}\right]\left[\mathrm{NTf}_{2}\right]$ base IL and NEILs over $25-345^{\circ} \mathrm{C}$ with an interval of $10^{\circ} \mathrm{C}$ is presented in Fig.9(b). It is clear from the Fig.9(b) that the heat capacity of NEILs is much higher than the base IL over the measured temperature range and the heat capacity increases almost 
linearly with temperature. The average enhancements of heat capacity are $\sim 9 \%, \sim 28 \%$, and $\sim 62 \%$ of $0.5,1$, and $2.5 \mathrm{wt} \%$ NEILs respectively. Measured heat capacities of NEILs were compared with the existing classical theoretical model of heat capacity for a mixture where base IL and nanoparticles are assumed at thermal equilibrium [46]:

$c_{p, N E I L}=\frac{\phi_{n} \rho_{n} C_{p, n}+\phi_{B L} \rho_{B L} C_{p, B L}}{\phi_{n} \rho_{n}+\phi_{B L} \rho_{B L}}$

where, $c_{p, N E I L}, c_{p, n}=0.791 \mathrm{~J} / g . K$, and $c_{p, B L}$ are the heat capacity of NEILs, nanoparticles, and base IL respectively, $\phi$ is the nanoparticles volume fraction. $\rho_{n}$ and $\rho_{B L}$ are the density of nanoparticles and base IL respectively. Most of the previous studies for water based nanofluids show lower heat capacity and are predicted well by the theoretical model [47]. But based on the equation, the predicted heat capacity of NEILs shows slightly lower value than the base IL whereas the experimental measured heat capacity of NEILs shows much higher value compared to the base ILs. That means the model failed to predict the significant enhancement of heat capacity of NEILs and more sophisticated investigations will be required to explain these enhancements. Meanwhile, the significant enhancement in heat capacity of NEILs was observed by Bridges et al. [17] where NEILs was synthesized with $\left[\mathrm{C}_{4} \mathrm{mmim}\right]\left[\mathrm{NTf}_{2}\right] \mathrm{IL}$ and spherical $\mathrm{Al}_{2} \mathrm{O}_{3}$ nanoparticles. Nieto de Castro et al. [20] also reported up to 8\% enhancement heat capacity of IoNanofluids ([ $\left.\mathrm{C}_{4} \mathrm{mim}\right]\left[\mathrm{PF}_{6}\right]+1 \mathrm{wt} \%$ MWCNTs). Shin et al. [44] have reported $\sim 26 \%$ enhancement of heat capacity with $1 \mathrm{wt} \%$ of silica nanoparticles in eutectic of lithium carbonate and potassium carbonate (62:38 ratio) and proposed that the enhancement is due to the high specific surface energy of nanoparticles. In another observation, Shin et al. [29] proposed three independent models to discuss the heat capacity enhancement, including (i) higher specific heat capacity of nanoparticles than bulk material, (ii) solid-fluid interaction energy, and (iii) liquid molecule layer in nanoparticles. In addition to those models, Tiznobaik et al. [48] observed that there are needle-like structure forms in nanofluids that have a high specific surface area and contributing in high heat capacity of nanofluids. For NEILs as was discussed in section 3.1 and 3.2, the complex interaction between nanoparticles surface and ILs may also play a role in the enormous enhancement of heat capacity. However, the heat capacity enhancement of NEILs will help to develop energy efficient heat transfer fluids for the next generation CSP system. 


\section{CONCLUSIONS}

Thermophysical properties of four different $\mathrm{Al}_{2} \mathrm{O}_{3}$ nanoparticle enhanced ionic liquids (NEILs) at different concentrations $(0.5,1.0$, and $2.5 \mathrm{wt} \%)$ were measured experimentally and reported. All of the NEILs show shear thinning behavior and shear thinning behavior occurs at all measured temperatures. NEILs shows enormous enhancement of shear viscosity with a small volume percentage of nanoparticles and viscosity decreasing sharply with temperature increases. The experimental enhanced viscosity of NEILs predicted well by considering the aggregation model with high aggregation factor $\left(\frac{a_{a}}{a}=21.5\right)$.

Thermal conductivity also increases with nanoparticle concentration and shows up to $\sim 11 \%$ enhancement for $2.5 \mathrm{wt} \%$ NEILs. The thermal conductivity of ILs and NEILs does not show much temperature dependency. The effective thermal conductivity of NEILs was underpredicted with the same aggregation factor. The better prediction of the effective thermal conductivity was found by considering interfacial layer of nanoparticles on NEILs.

Heat capacity of NEILs shows huge enhancements compared to base ILs and up to $~ 62 \%$ enhancement was reported for $2.5 \mathrm{wt} \%$ NEILs. The theoretical model for heat capacity failed to predict the experimental results. However, to explain the exact mechanism of thermophysical properties enhancement, there is needed more sophisticated theoretical model which considers the strong interaction of nanoparticles surface with ILs ions. Although the exact mechanism of enhancement is under investigation, these enhanced thermophysical properties of NEILs will help to develop energy efficient HTF for the next generation CSP system.

\section{ACKNOWLEDGEMENTS}

The financial support for this research is from the Department of Energy (DOE) Solar Energy Technology Program. The Savannah River National Laboratory is operated by Savannah River Nuclear Solutions. This document was prepared in conjunction with work accomplished under Contract No. DEAC09-08SR22470 with the U.S. Department of Energy.The author would like to thank Dr. Nirupam Aich of Dr. Navid Saleh group for helping in DLS measurements and Dr. Fang Yang from Dr. Guiren Wang group for helping in optical image. 


\section{RFERENCES}

[1] H. H. Khoo, R. B. H. Tan, Environmental Impact Evaluation of Conventional Fossil Fuel Production (Oil and Natural Gas) and Enhanced Resource Recovery with Potential $\mathrm{CO}_{2}$ Sequestration, Energy \& Fuels. 20 (2006)1914-1924.

[2] A. V. Herzog, T. E. Lipman, D. M. Kammen, "Renewable Energy Sources," in Our Fragile World: Challenges and Opportunities for Sustainable Development, forerunner to the Encyclopedia of Life Support Systems (EOLSS), Vol.1, Section 1 (UNESCO-EOLSS Secretariat, EOLSS Publishers Co. Ltd.,) (2001).

[3] Y. Chu, Review and Comparison of Different Solar Energy Technologies, Global Energy Network Institute (GENI) Annual Report (2011).

[4] S. A. Kalogirou, Solar thermal collectors and applications, Progress in Energy and Combustion Science. 30 (2004) 231-295.

[5] S. Pool, J. D.Passos Coggin, Fulfilling the Promise ofConcentrating Solar Power: Low-Cost Incentives Can SpurInnovation in the Solar Market (2013).

[6] M. Ashouri, A. M. K. Vandani, M. Mehrpooya, M. H. Ahmadi, A. Abdollahpour, Technoeconomic assessment of a Kalina cycle driven by a parabolic Trough solar collector, Energy Conversion and Management 105 (2015) 1328-1339.

[7] M. Ashouri, F. R. Astaraei, R. Ghasempour, M.H. Ahmadi, M. Feidt, Thermodynamic and economic evaluation of a small-scale organic Rankine cycle integrated with a concentrating solar collector, International Journal of Low-Carbon Technologies (2015), doi: 10.1093/ijlct/ctv025.

[8] S. L, Abiecunas J. O'Connell R. Economic, Energy, and Environmental Benefits of Concentrating Solar Power in California. Subcontract Report, NREL/SR-550-39291, April 2006.

[9] Therminol VP-1, Technical Bulletin 7239115c; Solutia: St. Louis,MO, 2008.

[10] D. Kearney, U. Herrmann, P. Nava, B. Kelly, R. Mahoney, J. Pacheco, R. Cable,N. Potrovitza, D. Blake, H. Price, Assessment of a molten salt heat transfer fluidin a parabolic trough solar field, Journal of Solar Energy Engineering. 125 (2003) 170-176.

[11] L. Moens, D. M. Blake, Mechanism of hydrogen formation insolar parabolic trough receivers. 14th Biennial CSPSolarPACES (Solar Power and Chemical Energy Systems) Symposium,Las Vegas, NV, March 4-7, 2008. 
[12] T. C. Paul, AKM. M. Morshed, E. B. Fox, A. E. Visser, N. J. Bridges, J. A. Khan, Buoyancy driven heat transfer behavior of [C4mim][NTf2] ionic liquid: An experimental study, Applied Thermal Engineering. 66 (2014) 534-540.

[13] T. Welton,Room-Temperature Ionic Liquids: Solvents for Synthesis and Catalysis,Chemical Reviews. 99(1999) 2071-2083.

[14] H. L. Ngo, K. LeCompte, L. Hargens, A. B. McEwen, Thermal properties of imidazolium ionic liquids, ThermochimicaActa357-358 (2000) 97-102.

[15] F. Endres, S. Z. El Abedin, Air and water stable ionic liquids in physical chemistry, Physical Chemistry Chemical Physics. 8(2006) 2101-2116.

[16] E. B. Fox, A. E. Visser, N. J. Bridges, J. W. Amoroso, Thermophysical Properties of Nanoparticle-Enhanced Ionic Liquids (NEILs) Heat-Transfer Fluids,Energy Fuels.27(6) (2013) 3385-3393.

[17] N. J. Bridges, A. E. Visser, E. B. Fox, Potential of Nanoparticle-Enhanced Ionic Liquids (NEILs) as AdvancedHeat-Transfer Fluids,Energy\& Fuels. 25(10) (2011) 4862-4864.

[18] T. C. Paul, A.K.M. M. Morshed, E. B. Fox, J. A. Khan, Thermal performance of $\mathrm{Al}_{2} \mathrm{O}_{3}$ Nanoparticle Enhanced Ionic Liquids (NEILs) for Concentrated Solar Power (CSP) applications, International Journal of Heat and Mass Transfer 85 (2015) 585-594.

[19] T. C. Paul, A.K.M. M. Morshed, E. B. Fox, J. A. Khan, Experimental investigation of natural convection heat transfer of $\mathrm{Al}_{2} \mathrm{O}_{3}$ Nanoparticle Enhanced Ionic Liquids (NEILs), International Journal of Heat and Mass Transfer 83 (2015) 753-561.

[20] C. A. Nieto de Castro, M. J. V. Lourenco, A. P. C. Ribeiro, E. Langa, and S. I. C. Vieira, Thermal Properties of Ionic Liquids and IoNanofluids of Imidazolium and Pyrrolidinium Liquids, Journal of Chemical Engineering Data. 55(2010) 653-661.

[21] B Wang, X. Wang, W. Lou and J. Hao, Gold-ionic liquid nanofluids with preferably tribological properties and thermal conductivity, Nanoscale Research Letters.(2011) 6:259.

[22] F. Wang, L. Han, Z. Zhang, X. Fang, J. Shi, W. Ma, Surfactant-free ionic liquid-based nanofluidswithremarkable thermal conductivity enhancement atvery low loading of graphene, Nanoscale Research Letters.(2012) 7:314.

[23] A. Menbari, A. A. Alemrajabi, A. Rezaei, Heat transfer analysis and the effect of $\mathrm{CuO} /$ Water nanofluid on direct absorption concentrating solar collector, Applied Thermal Engineering 104 (2016) 176-183. 
[24] io-li-tec (Ionic Liquids Technologies): http://www.iolitec-usa.com/, 2016 (accessed 05.05.16).

[25] Sigma-aldrich: http://www.sigmaaldrich.com/catalog/product/aldrich/702129?lang=en\& region=US, 2016 (accessed 05.15.16).

[26] Brookfield Engineering Co.: http://www.brookfieldengineering.com/products/viscometers/, 2016 (accessed 05.15.16).

[27] Decagon Device, USA: https://www.decagon.com/en/thermal/instruments/kd2-pro/, 2016 (accessed 05.15.16).

[28] TA instruments Inc.: http://www.tainstruments.com/q2000/ , 2016 (accessed 05.15.16).

[29] D. Shin, D. Banerjee, Enhancement of specific heat capacity of high-temperature silicananofluids synthesized in alkali chloride salt eutectics for solar thermal-energy storage applications" International Journal of Heat and Mass Transfer. 54(2011) 1064-1070.

[30] H. Chena, Y. Ding, Y. He, C. Tan, Rheological behaviour of ethylene glycol based titania nanofluids, Chemical Physics Letters 444 (2007) 333-337.

[31] A. Einstein, EineneueBestimmung der Molekuldimensionen, ,Annalen der Physik 19 (1906) 289-306.

[32] H.C. Brinkman, The viscosity of concentrated suspensions and solutions, Journal of ChemistryPhysics. 20(1952)571-581.

[33] G. K. Bachelor, The effect of Brownian motion on the bulkstress in a suspension of spherical particles, Journal of Fluid Mechnics.83 (1977)97-117.

[34] L.E. Niesen, Generalized equation for the elastic moduli ofcomposite materials, Journal of AppliedPhysics.41 (1970) 4626- 4627.

[35] I. M. Krieger, T. J. Dougherty, A mechanism for non-Newtonian flow in suspensions of rigid spheres, Transactions of the society of Rheology, 3(1959), 137-152.

[36] B. Jo, S. Jung,D. Shin, D. Banerjee, Anomalous rheological behavior of complex fluids (nanofluids), Proceedings of the International Mechanical Engineering Congress \& Exposition IMECE2011 November 11-17, Denver, Colorado, USA.

[37] S-P Jang, S. U. S. Choi, Role of Brownian motion in the enhanced thermal conductivity of nanofluids, Applied Physics Letters. 44 (21)(2004) 4316-4318.

[38] K.C. Leong, C. Yang, S.M.S. Murshed, A model for the thermal conductivity of nanofluids - the effect of interfacial layer, Journal of Nanoparticle Research. 8(2006)245-254. 
[39] H. Li, L. Wang, Y. He, Y. Hu, J. Zhu, B. Jiang, Experimental investigation of thermal conductivity and viscosity of ethylene glycol based $\mathrm{ZnO}$ nanofluids, Applied Thermal Engineering. 88 (2015) 363-368.

[40] J.C. Maxwell, Electricity and Magnetism. ClarendonPress (1873), Oxford, UK.

[41] D.A.G. Bruggeman, BerechnungVerschiedenerPhysikalischerKonstanten von HeterogenenSubastanzen der MischkorperausIsotropenSubstanzen. Annalen der Physik. Leipzig 24 (1935) 636-679.

[42] M. Kh. Abdolbaqi, W.H. Azmi, R. Mamat, K.V. Sharma, G. Najafi, Experimental investigation of thermal conductivity and electrical conductivity of BioGlycol-water mixture based $\mathrm{Al}_{2} \mathrm{O}_{3}$ nanofluid, Applied Thermal Engineering. 102 (2016) 932-941.

[43] S.M.S. Murshed, K.C. Leong, C. Yang, Investigations of thermal conductivity and viscosity of nanofluids, International Journal of Thermal Sciences. 47 (2008) 560-568.

[44] A. S. Pensado, A. A. H. Padua, Solvation and stabilization ofmetallic nanoparticles in ionic liquids, Angewandte Chemie International Edition.50(37) (2011) 8683-8687.

[45] W. R. Carper, P. G. Wahlbeck, N. S. Nooruddin, Semi-Empirical Molecular Modeling of Ionic Liquid Tribology:Ionic Liquid-Aluminum Oxide Surface Interactions, Tribology Letters 43(2011)163-168.

[46] M. Xing, J. Yu, R. Wang, Thermo-physical properties of water-based single-walled carbon nanotube nanofluid as advanced coolant, Applied Thermal Engineering. 87 (2015) 344-351.

[47] D. Shin, D. Banerjee, Enhanced Specific Heat of Silica Nanofluid, Journal of Heat Transfer. 133(2011) 024501.

[48] H.Tiznobaik, D. Shin, Enhanced specific heat capacity of high-temperature molten saltbased nanofluids, International Journal of Heat and Mass Transfer. 57(2013)542-548. 


\section{List of Figures:}

Figure 1: Chemical structure of cation and anion of all ionic liquids

Figure 2: Sysnthesis of NEILs, IL sample, SEM image, vortex mixture, and NEILs sample

Figure 3: Rheological behavior of a) base $\left[\mathrm{C}_{4} \mathrm{mmim}\right]\left[\mathrm{NTf}_{2}\right] \mathrm{IL}$ and NEILs at $\left.30^{\circ} \mathrm{C} \mathrm{b}\right) 0.5 \mathrm{wt} \%$ $\mathrm{Al}_{2} \mathrm{O}_{3}$ loading of four ILs c) $1 \mathrm{wt} \%\left[\mathrm{C}_{4} \mathrm{mmim}\right]\left[\mathrm{NTf}_{2}\right]$ NEILs at different temperature d) viscosity of $\left[\mathrm{C}_{4} \mathrm{mmim}\right]\left[\mathrm{NTf}_{2}\right]$ NEILs as a function of temperature, e) viscosity of $\left[\mathrm{C}_{4} \mathrm{mmim}\right]\left[\mathrm{NTf}_{2}\right] \mathrm{NEILs}$ compared with equation

Figure 4: Viscosity of four base ILs and NEILs at $30^{\circ} \mathrm{C}$

Figure 5: Effective viscosity as a function of nanoparticle volume fraction

Figure 6: Optical image of $0.5 \mathrm{wt} \%$ NEILs

Figure 7: Nanoparticle size with respect to time

Figure 8: (a) Thermal conductivity of all four ILs and NEILs, (b) Thermal conductivity of $\left[\mathrm{C}_{4} \mathrm{mmim}\right]\left[\mathrm{NTf}_{2}\right]$ NEILs as a function of temperature and (c) Thermal conductivity as function of nanoparticles volume fraction

Figure 9: (a) Heat capacity of all ILs and NEILs at $30^{\circ} \mathrm{C}$, (b) Heat capacity of $\left[\mathrm{C}_{4} \mathrm{mmim}\right]\left[\mathrm{NTf}_{2}\right]$ NEILs as a function of temperature 
Figure 1:

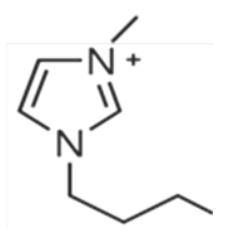

$\left[\mathrm{C}_{4} \mathrm{mim}\right]^{+}$

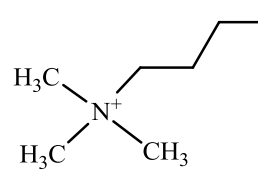

$\left[\mathrm{N}_{4111}\right]^{+}$

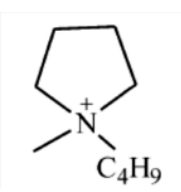

$\left[\mathrm{C}_{4} \text { mpyrr }\right]^{+}$

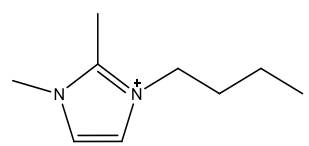

$\left[\mathrm{C}_{4} \mathrm{mmim}\right]^{+}$

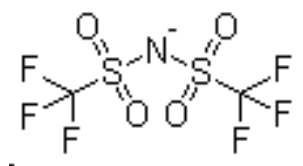

$\left[\mathrm{NTf}_{2}\right]^{-}$

Anion 
Figure 2:

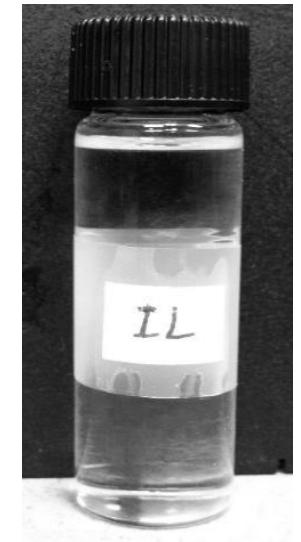

Base ionic liquid

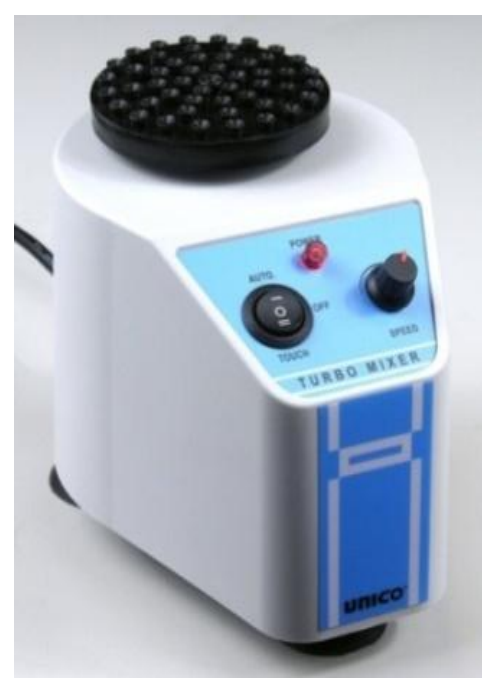

Vortex mixture

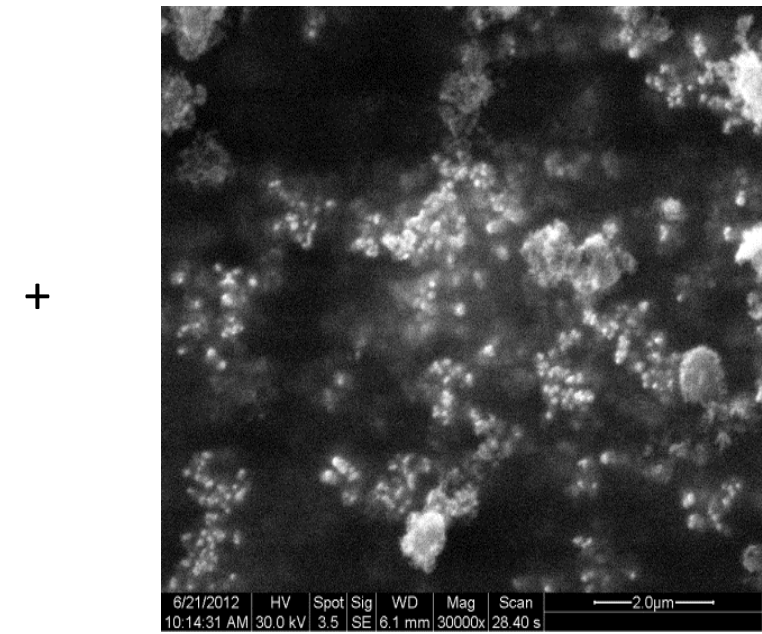

SEM image of $\mathrm{Al}_{2} \mathrm{O}_{3}$ nanoparticles

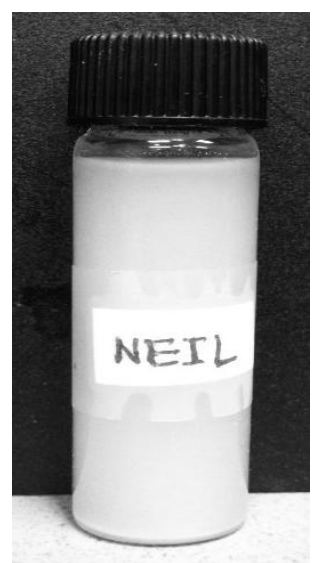

Nanoparticle Enhanched Ionic Liquids (NEILs) 
Figure 3:

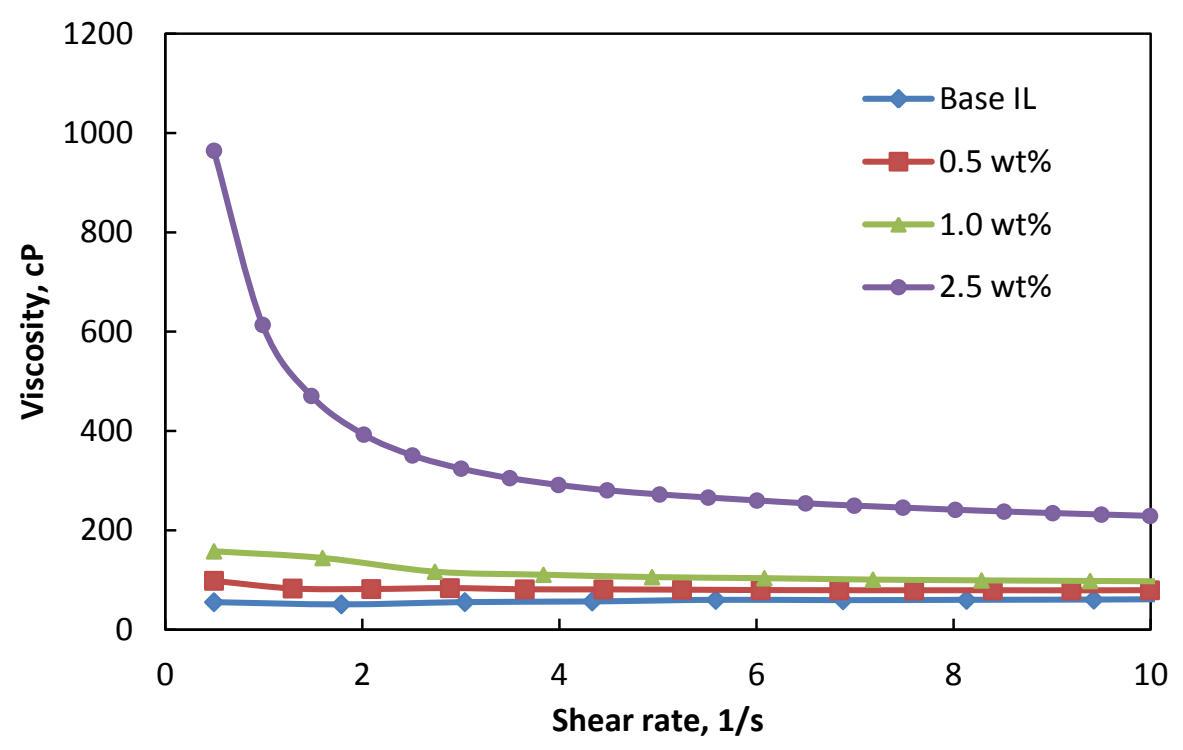

(a)

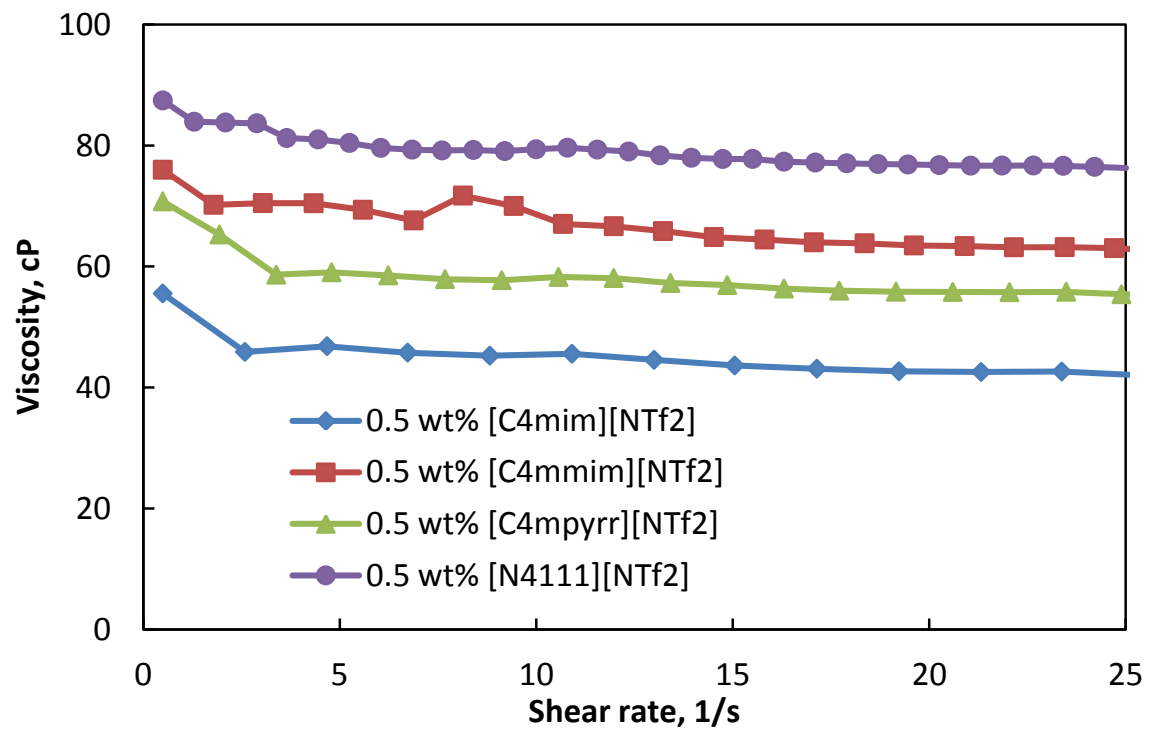

(b) 


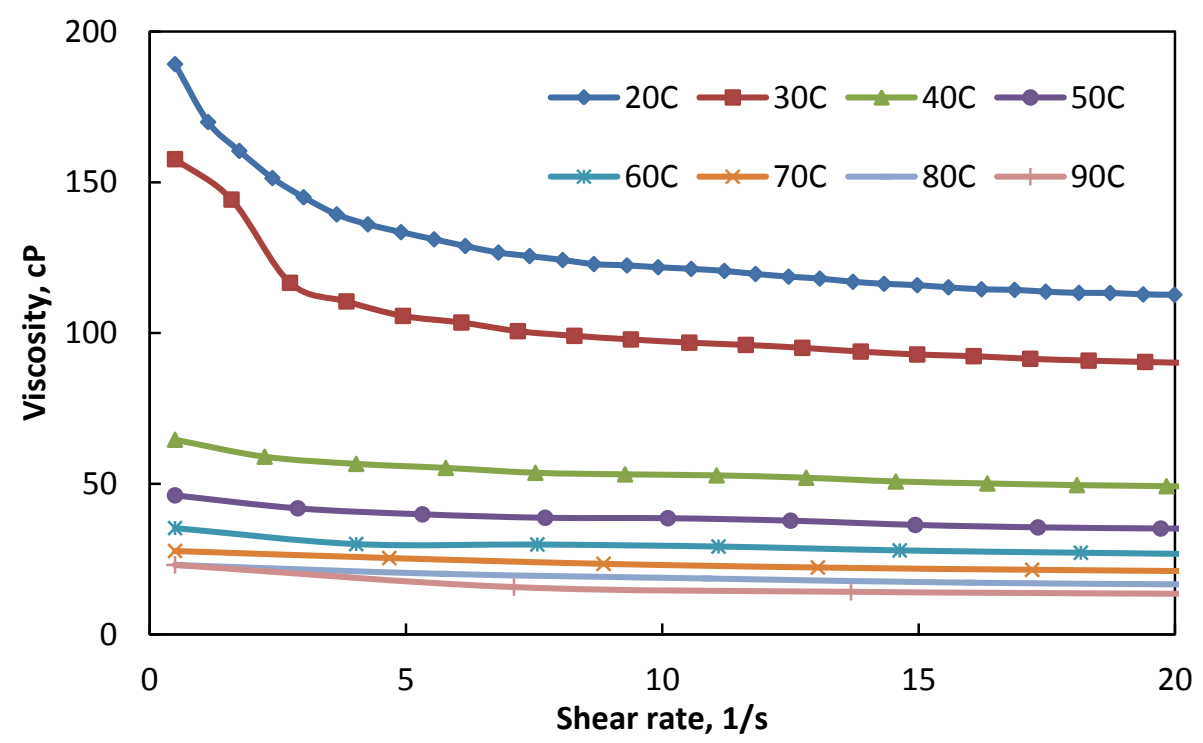

(c)

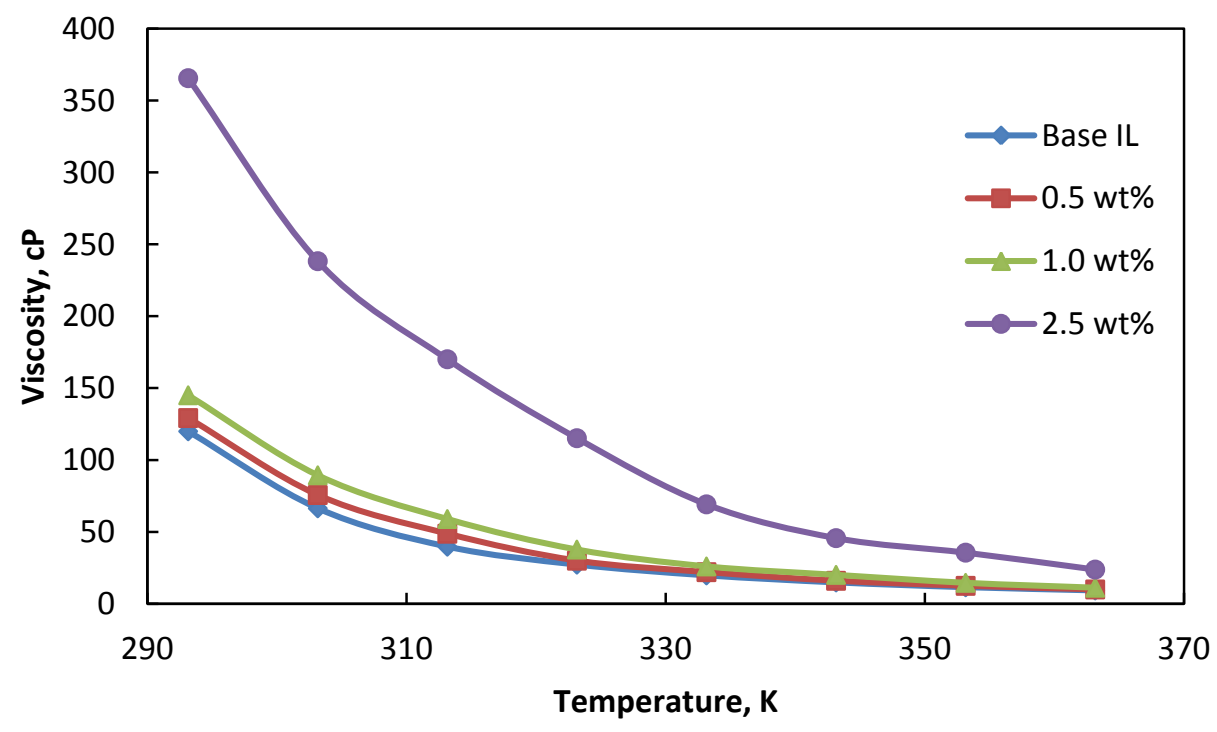

(d) 


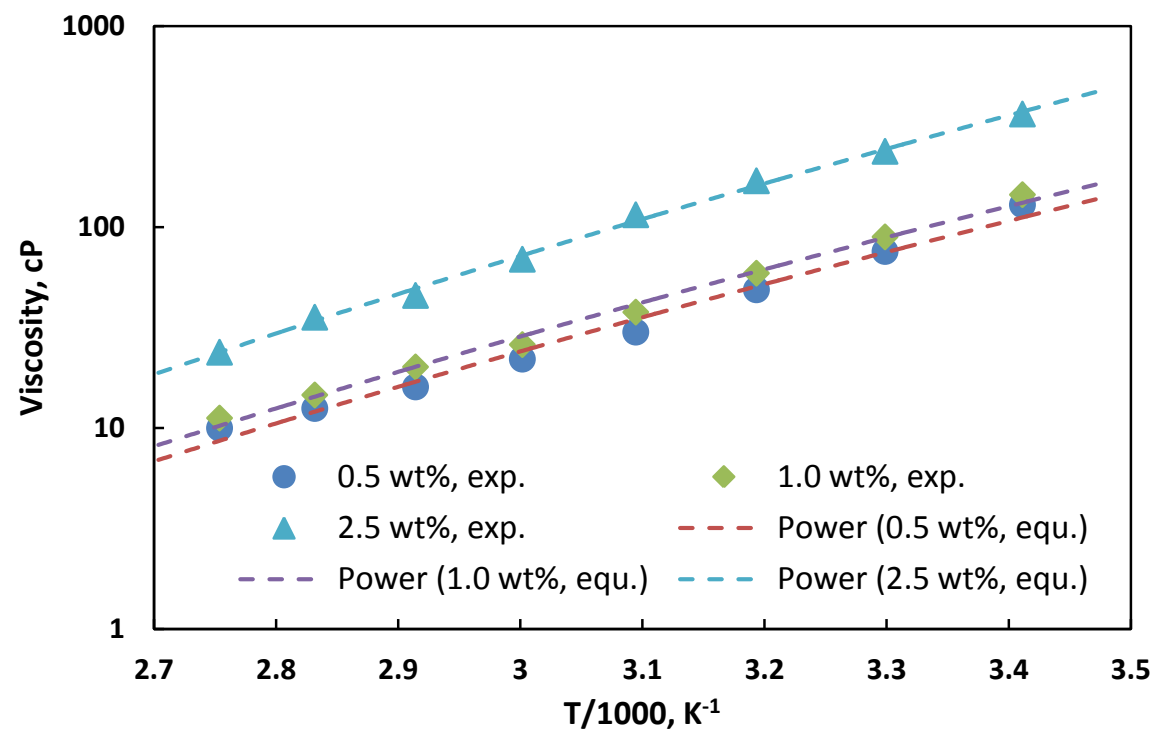

(e) 
Figure 4:

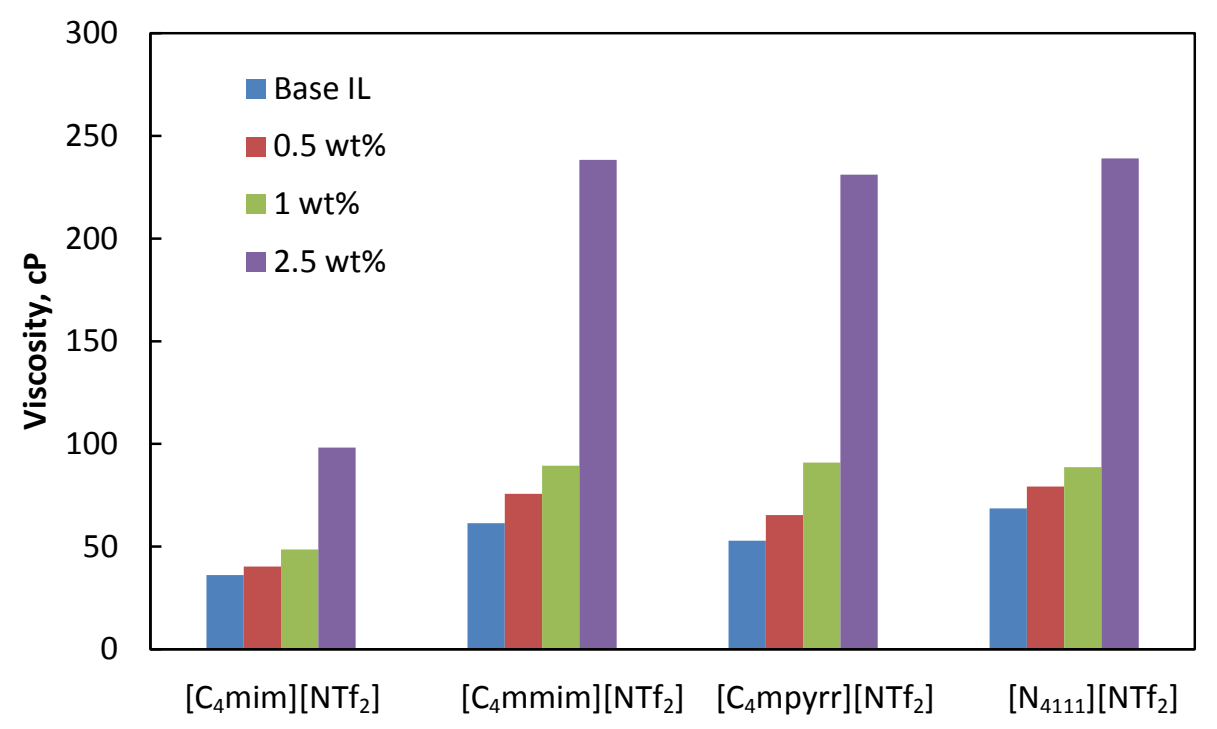


Figure 5:

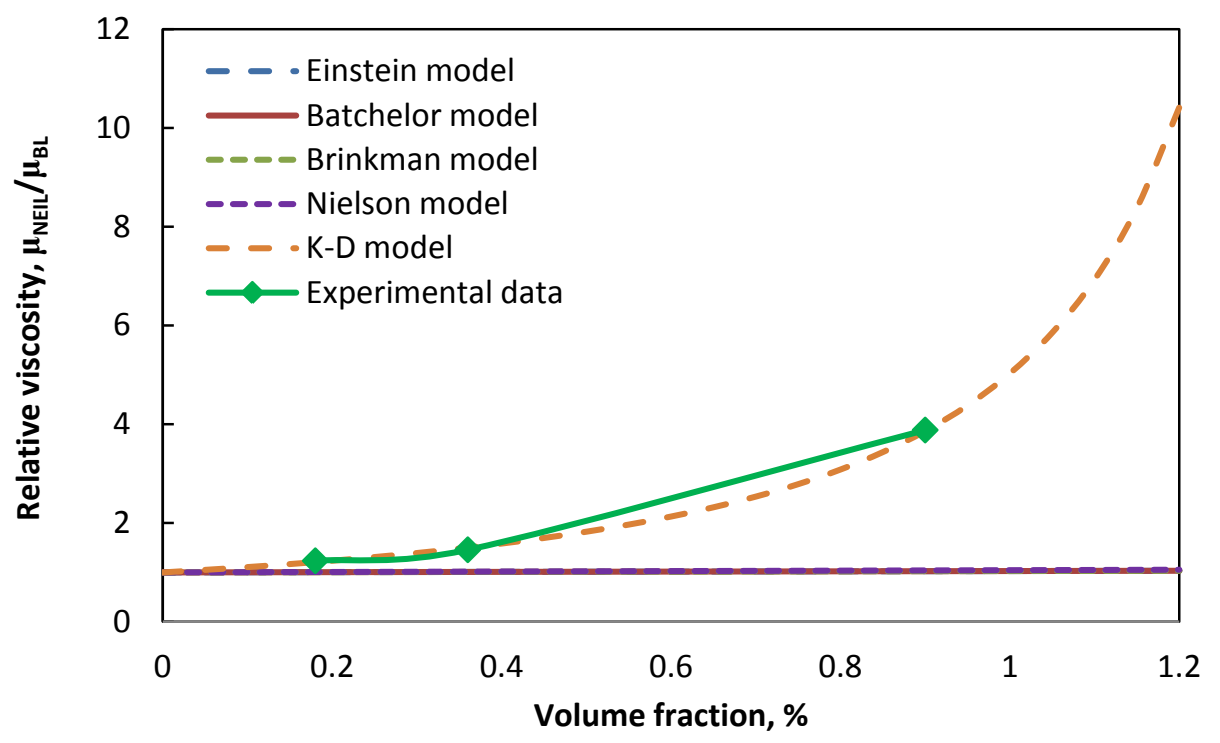


Figure 6:

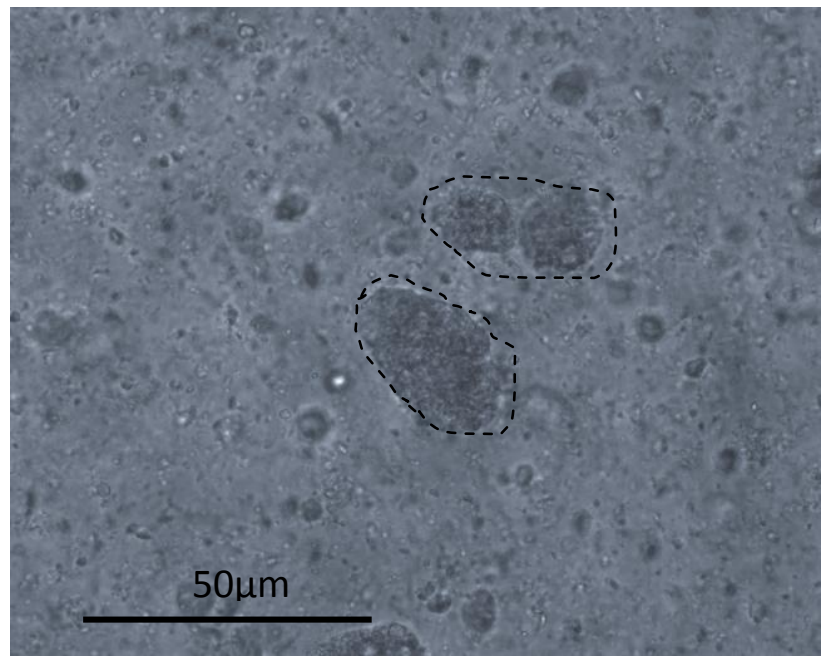


Figure 7:

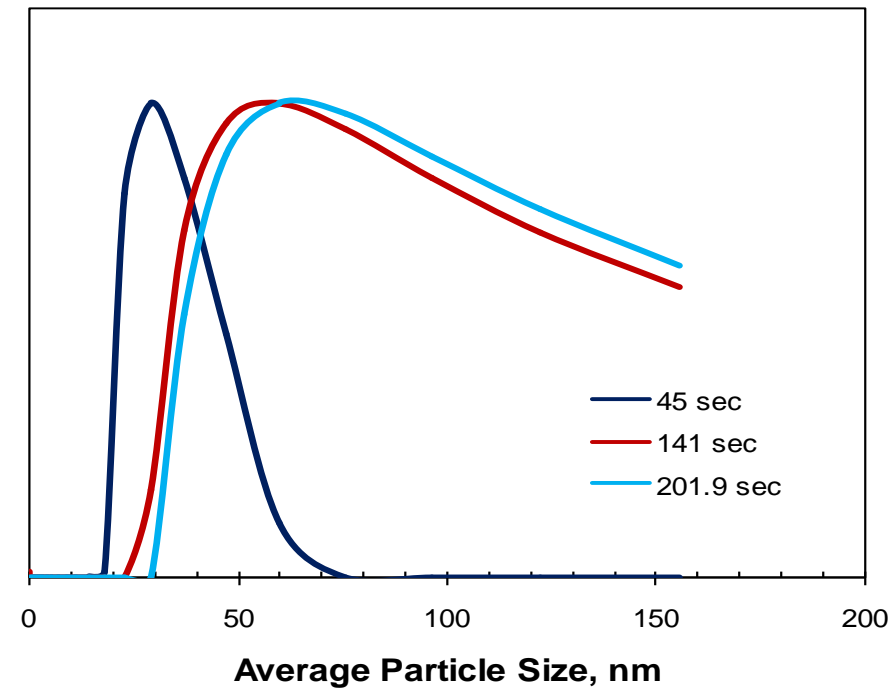


Figure 8:

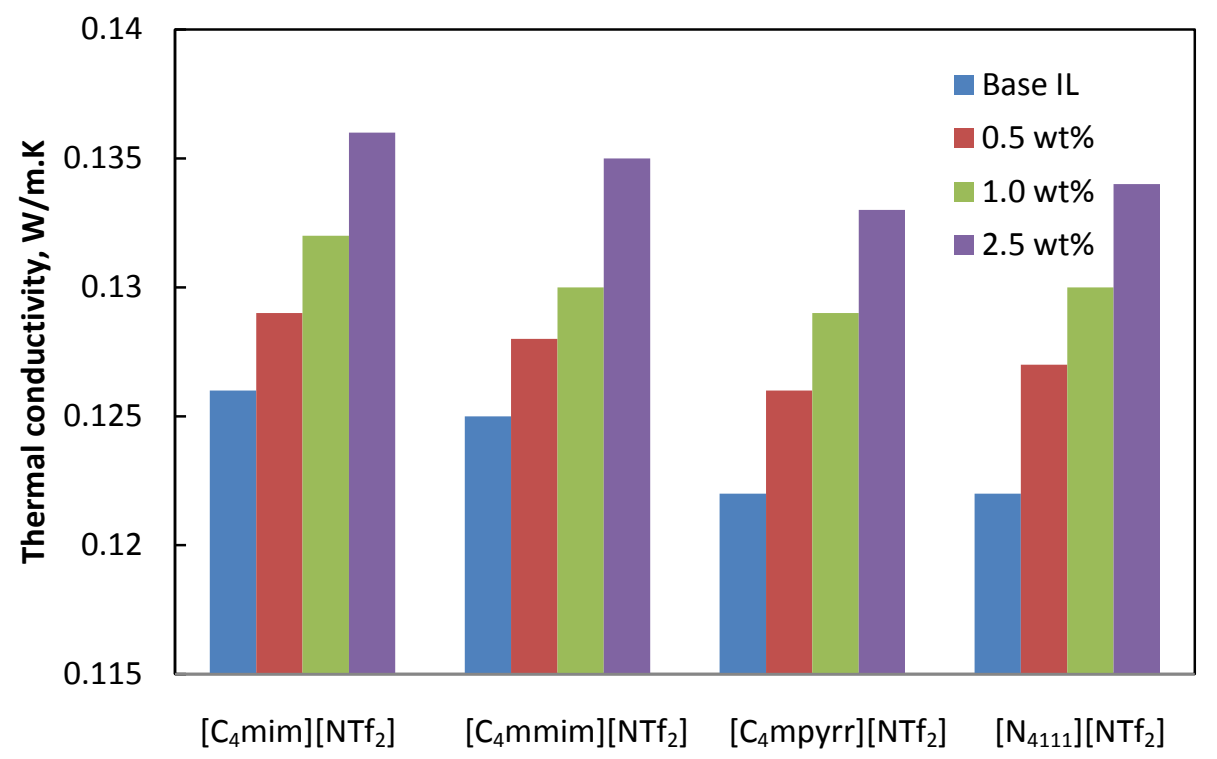

(a)

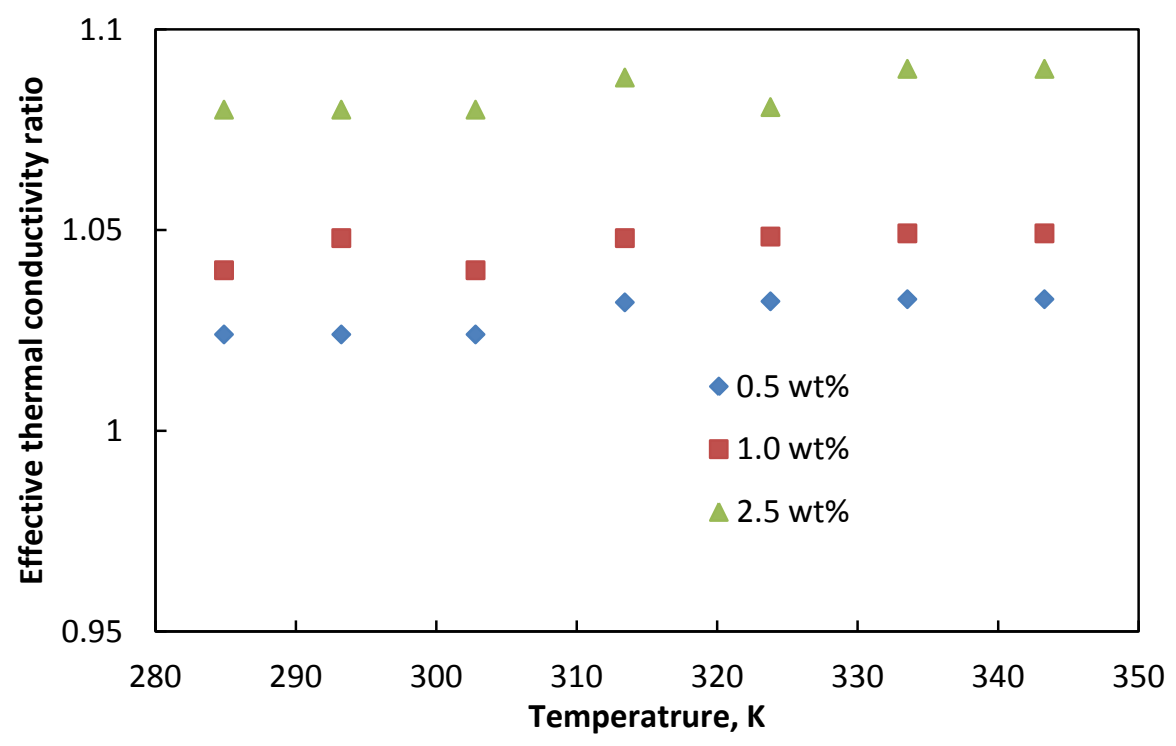

(b) 


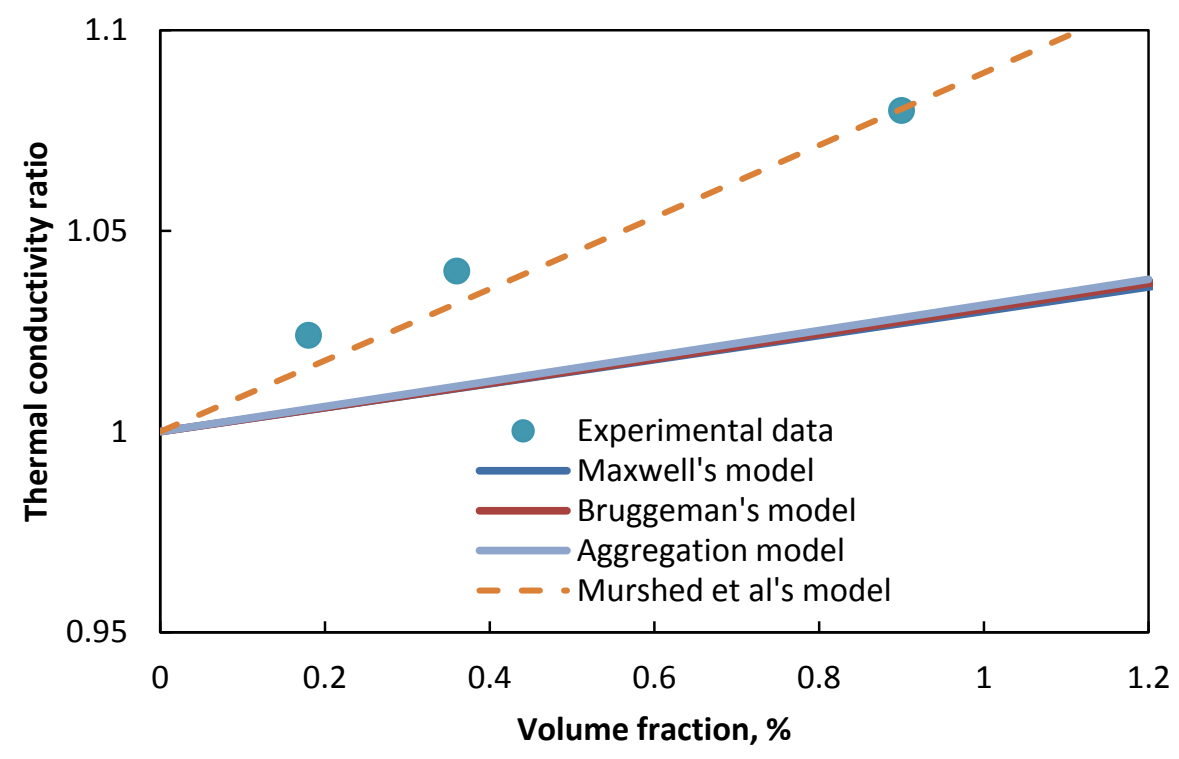

(c) 
Figure 9:

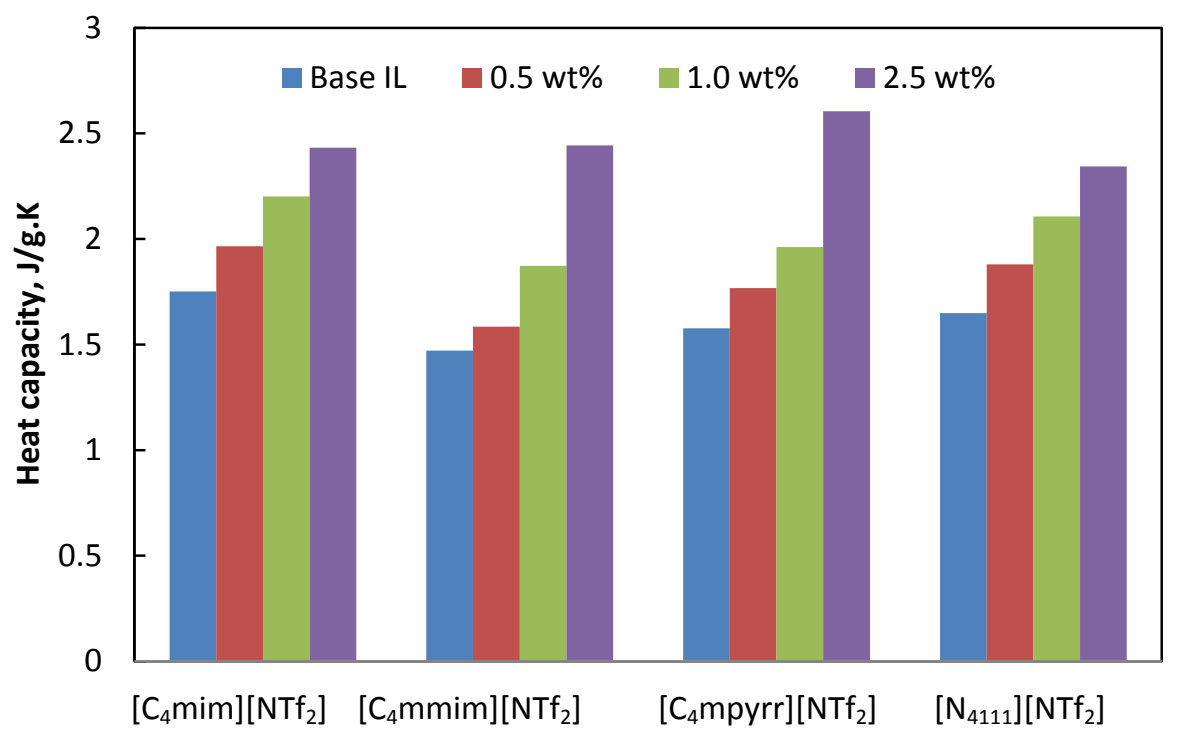

(a)

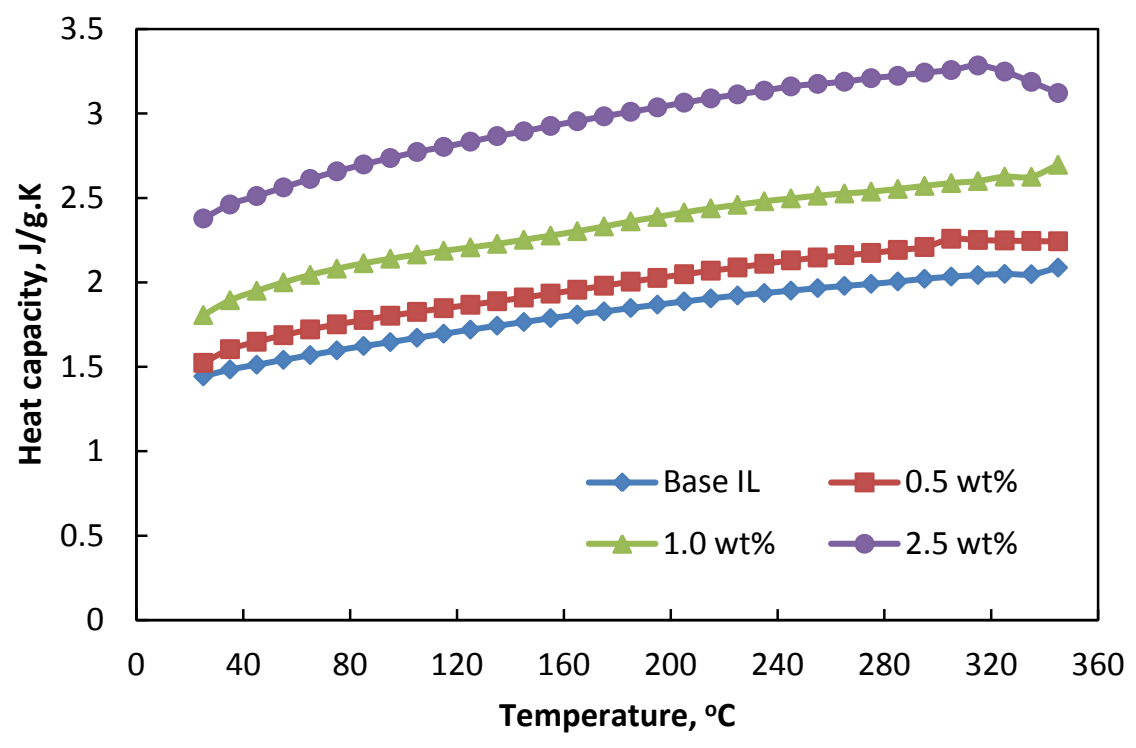

(b) 